\title{
Impaired lipid transport in gestational diabetes mellitus
}

\author{
Shannon K Flood Nichols ${ }^{1 \dagger}$, Monica A Lutgendorf ${ }^{1 \dagger}$, Mariano T Mesngon ${ }^{2}$, Alexis J Harroun², Maria S Cesarini ${ }^{2}$, Peter G Napolitano ${ }^{1}$ \\ and Danielle L Ippolito ${ }^{2^{*}}$ \\ *Correspondence: Danielle.Ippolito@gmail.com \\ ${ }^{\dagger}$ These authors contributed equally to this work. \\ 'Division of Maternal-Fetal Medicine, Department of Obstetrics and Gynecology, Madigan Army Medical Center, 9040 Fitzsimmons \\ Drive, Tacoma, WA 98431, USA. \\ ${ }^{2}$ Department of Clinical Investigation, Madigan Army Medical Center, 9040 Fitzsimmons Drive, Tacoma, WA 98431, USA.
}

\begin{abstract}
Background: Gestational diabetes mellitus (GDM) complicates 5-6\% of pregnancies, placing affected individuals at higher risk for pregnancy-related complications and persistent metabolic and cardiovascular disorders later in life. In this study, we evaluated the association between apolipoproteins and plasma cholesterol levels in patients with gestational diabetes compared to uncomplicated controls over the course of pregnancy.

Methods: Plasma was prospectively collected from 311 nulligravid women during 3 time periods during pregnancy (4-12, 16-22 and 24-28 weeks gestation). Mass spectrometry and enzyme-linked immunosorbant assays (ELISA) were used to measure the relative and absolute changes in apolipoprotein abundance. High density lipoprotein (HDL) and very low/low density lipoprotein (LDL/VLDL) cholesterol levels were quantified by enzymatic assay. Mann Whitney $U$ tests were used to determine statistical significance ( $p<0.05$ ).

$\underline{\text { Results: }}$ Five cases of GDM were identified (mean 1-hour blood glucose concentration = $163.2+/-7.3 \mathrm{mg} / \mathrm{dL}$ ). In the control subjects, plasma concentrations of Apo A-II measured by ELISA marginally increased from 4-12 weeks to 24-28 weeks, while concentrations did not significantly increase in GDM subjects. Likewise, VLDL/LDL cholesterol levels increased in the controls but not in the GDM cohort ( $\mathrm{p}=0.005)$. HDL cholesterol was not significantly different between cohorts. Mass spectrometry spectral patterns identified Apo A-II dimers, Apo A-II monomers and 3 forms of Apo C-III (asialylated Apo C-III, monosialylated Apo C-III and disialylated Apo C-III $)_{2}$ in patient plasma. In GDM cases, Apo A-II dimers were significantly lower than controls in the second trimester $(\mathrm{p}<0.05)$. While both Apo A-II monomer and asialylated Apo C-III increased steadily over gestational time in the control subjects ( $<<0.05$ ), GDM cases showed no statistical change in either protein between trimesters 1, 2 and 3.

Conclusions: The rate of change over gestational time for the apolipoproteins and VLDL/LDL cholesterol was significantly lower in GDM cases than uncomplicated controls, indicating that the normal hyperlipidemia of pregnancy is disrupted in GDM. Our results support a role for impaired lipid transport and homeostasis in GDM and may suggest a potential diagnostic and therapeutic target.

Keywords: Gestational diabetes mellitus, apolipoproteins, cholesterol, lipid, diagnostic
\end{abstract}

\section{Introduction}

Approximately $5-6 \%$ of pregnancies are complicated by gestational diabetes mellitus (GDM). The incidence of the disease is even higher in developed countries, largely due to the rising obesity epidemic and the number of women with a body mass index (BMI) greater than 32 who become pregnant [1]. Gestational diabetes is associated with an increased risk for several maternal and fetal morbidities including stillbirth, fetal macrosomia, shoulder dystocia, increased risk for cesarean section and neonatal electrolyte abnormalities [2]. There is also an increased risk of complications after pregnancy including childhood obesity in the neonates and the development of cardiovascular disease and diabetes in the mothers $[2,3]$. GDM is characterized by glucose intolerance in previously euglycemic individuals and is diagnosed in the late second trimester by a glucose challenge test $[\mathbf{2}, \mathbf{4}]$. Earlier detection and treatment has been proposed to improve maternal and fetal outcomes in women deemed to be at increased risk for GDM, but a consistently recommended early screening test beyond the glucose challenge test is not currently available $[5,6]$.
Mass spectrometry is a sensitive method for early detection of subtle changes in the plasma proteome during pregnancy and has the potential to identify women at risk for certain pregnancy complications even before the onset of clinical symptoms $[7,8]$. Our laboratory recently described a mass spectrometry approach measuring post-translational modifications in maternal apolipoproteins for preclinical diagnosis of adverse obstetric outcomes [9]. Since GDM is characterized by a progressive disruption in metabolic carbohydrate-lipid balance, we hypothesized that changes in the apolipoproteins could be used to distinguish GDM cases from controls early in pregnancy. In this study, we prospectively compared apolipoprotein profiles in cases of gestational diabetes and uncomplicated controls throughout pregnancy using both biochemical and mass spectrometry methods.

\section{Methods \\ Subjects}

The study was approved by the Madigan Army Medical Center Institutional Review Board. A total of 311 nulliparous women 
were approached for study participation at their Obstetrics intake appointment (4-12 weeks gestation). All subjects provided informed consent. Patients were excluded from participation if they had a history of chronic illness, had previously delivered a live child, were transferring to a different medical center before delivery, presented later than 12 weeks gestation, or received infertility treatment to achieve pregnancy.

\section{Clinical assessment}

Antenatal records were reviewed and demographic variables at intake and obstetric outcomes after delivery were recorded. Patient body mass index, gestational age at intake and delivery, fetal weight at delivery, maternal weight and glucose challenge and tolerance test results were recorded for each subject from antenatal medical record review.

\section{Blood collection}

Blood was collected by venipuncture at 4-12, 16-22 and 24-28 weeks gestation. Plasma was isolated by centrifugation ( 15 minutes at $4^{\circ} \mathrm{C}, 1500 \times \mathrm{g}$ ). Plasma was mixed with protease inhibitor cocktail (Roche Diagnostics), aliquoted and stored at $-150^{\circ} \mathrm{C}$.

\section{Enzyme-linked immunosorbant assays}

Enzyme-linked immunosorbant assays with antibodies specific for Apolipoproteins A-II and C-III were performed according to manufacturer specifications (Assay Pro, St Charles, MO).

\section{Cholesterol quantification enzymatic assay}

VLDL/LDL and HDL cholesterol were quantified by colorimetric quantitative enzyme assay according to the manufacturer's instructions (BioVision, Milpitas, CA).

\section{Surface-enhanced laser desorption/ionization time-of-} flight mass spectrometry

Plasma was spotted in duplicate on weak cation exchange array surfaces, incubated for 30 minutes, then washed to remove unbound proteins. Sinapinic acid matrix was applied and proteins were desorbed from array surfaces using empirically determined laser energies. Time of flight from array surface to detector was measured and converted to protein mass by interpolation to calibrant standard curves. Apolipoprotein subtypes were identified by comparing empirically derived accurate masses with spectra reported in the literature as described $[7,9,10]$.

\section{Statistical analysis}

Graphpad Prism (GraphPad Software, San Diego, CA) was used to calculate statistical significance, with an a of 0.05 set as statistical significance. Repeated measures analysis of variance (ANOVA) was used to determine differences among longitudinal cohorts. Mann-Whitney $U$ tests were used to calculate differences among single variables.

\section{Results \\ Patient characteristics}

Of the 315 women approached for study participation, 311 agreed to participate and provided informed consent (response rate of 98\%). Seventy-five were not included in the final analysis for the following reasons: withdrew from the study $(n=8)$, did not deliver at Madigan $(n=44)$, electively terminated the pregnancy $(n=3)$, were lost to follow-up $(n=18)$, or were diagnosed with twins $(n=2)$. Seven of the remaining 235 patients met the clinical diagnostic criteria for GDM (3\%). Of these GDM subjects, 4 had all 3 gestational age range specimens available for analysis, 1 had 2 specimens (4-12 and 24-28 weeks) and 2 had only the 4-12 week specimen. We excluded the latter 2 patients from the analysis because longitudinal specimens were not available. Eight gestationally age-matched subjects with uncomplicated pregnancies were chosen as non-GDM controls. None of the women included in either cohort had a history of a fetal loss beyond the first trimester. Demographics of the study population are presented in Table 1. Parameters of maternal age, gestational age of delivery, race, gestational age at analysis, body mass index at enrollment and mode of delivery were not statistically different among the cohorts. Glucose tolerance tests were significantly higher in GDM cases than control subjects (Table 1).

\section{Total Apo A-II and Apo C-III}

Total plasma concentration of apolipoproteins A-II and C-III were determined by quantitative ELISA (Table 2) in first trimester and at diagnosis for GDM (24-28 weeks). Concentrations are reported as the median (95\% confidence interval) at 4-12 weeks and 24-28 weeks. The rate of change over gestational time approached statistical significance for Apo A-II concentrations ( $p=0.052, U=21.5)$ in the control subjects, but was not statistically significant in GDM subjects $(p=0.653, U=20.5)$. Concentrations of Apo C-III increased significantly over gestational time in both GDM ( $p=0.006$, $\mathrm{U}=12)$ and control subjects $(\mathrm{p}=0.0003, \mathrm{U}=8))$. There was no statistical difference between the controls and GDM subjects at any gestational time.

\section{Cholesterol quantification}

VLDL/LDL and HDL cholesterol were quantified at 4-12 weeks and 24-28 weeks (Table 3). VLDL/LDL cholesterol was slightly elevated in GDM subjects relative to controls at 4-12 weeks and significantly lower than controls at 24-28 weeks. VLDL/ LDL cholesterol increased between age ranges in both groups, but the rate of change was significantly higher in non-GDM controls $(p=0.00415, U=1)$ than in GDM cases $(p=0.149, U=7)$ (Table 3). The increase in HDL cholesterol over gestational time was likewise greater in controls than in GDM subjects, but the difference was not statistically significant (Table 3). Total concentrations of HDL were comparable at 4-12 weeks but marginally lower in GDM subjects than controls at 24-28 weeks. 
Flood Nichols et al. Journal of Diabetes Research \& Clinical Metabolism 2013, http://www.hoajonline.com/journals/pdf/2050-0866-2-22.pdf

Table 1. Demographics of the study population*

\begin{tabular}{|c|c|c|c|c|}
\hline & $\begin{array}{l}\text { Non GDM } \\
\text { Controls }(n=8)\end{array}$ & $\operatorname{GDM}(n=5)$ & P value ${ }^{* *}$ & $\begin{array}{l}\text { U value } \\
\text { (critical } U^{* *}\end{array}$ \\
\hline Maternal Age (years) & $24(2)$ & $25(5)$ & $>0.05$ & $16(8)$ \\
\hline $\begin{array}{l}\text { Gestational Age of } \\
\text { Delivery }\end{array}$ & $40(1)$ & $38(1)$ & $>0.05$ & $17.5(8)$ \\
\hline Baby Weight (G) & $3455(496)$ & $3055(422)$ & $>0.05$ & $11(6)$ \\
\hline Co-Morbidities & none & 1 IUGR, 1 mild preeclampsia & - & - \\
\hline Race & - & - & $>0.05$ & - \\
\hline Caucasian & 8 & 4 & - & - \\
\hline Other & 0 & 1 & - & - \\
\hline $\begin{array}{l}\text { Body Mass Index at } \\
\text { Enrollment }\end{array}$ & $28(3)$ & $26(4)$ & $>0.05$ & $19.5(8)$ \\
\hline$<25$ & 2 & 2 & - & - \\
\hline $25-30$ & 5 & 1 & - & - \\
\hline$>30$ & 1 & 2 & - & - \\
\hline \multicolumn{5}{|l|}{$\begin{array}{l}\text { Gestational Age at } \\
\text { Analysis (days)* }\end{array}$} \\
\hline 4-12 weeks & $8(1)$ & $9(1)$ & $>0.05$ & $20(8)$ \\
\hline 16-22 weeks & $16(1)$ & $17(2)$ & $>0.05$ & $18(8)$ \\
\hline 24-28 weeks & $28(1)$ & $27(1)$ & $>0.05$ & $20(8)$ \\
\hline $\begin{array}{l}\text { Glucose challenge test } \\
(\mathrm{mg} / \mathrm{dL})\end{array}$ & $94(15)$ & $168(14)$ & 0.0002 & $0(8)$ \\
\hline $\begin{array}{l}\text { Glucose tolerance test } \\
(\mathrm{mg} / \mathrm{dL})\end{array}$ & $\mathrm{n} / \mathrm{a}$ & $90(3)$ & - & - \\
\hline Fasting blood glucose & $\mathrm{n} / \mathrm{a}$ & $90(3)$ & - & - \\
\hline 1 hour & - & $205(11)$ & - & - \\
\hline 2 hours & - & $194(18)$ & - & - \\
\hline 3 hours & - & $115(28)$ & - & - \\
\hline Mode of Delivery & & & & -- \\
\hline Vaginal & 5 & 4 & - & - \\
\hline Cesarean secton & 3 & 1 & - & - \\
\hline
\end{tabular}

${ }^{*}$ continuous data expressed in median ( $95 \%$ confidence interval).

${ }^{*}$, $\mathrm{p}$ value calculated by analysis of variance for contiuous variables and Chi-square analysis for categorical variables.

$* * *$, critical value of $U$ for statistical significance at $\mathrm{p} \leq 0.05$.

\section{Apo A-II and Apo C-III subtype analysis by mass spectrometry}

ELISA assays measure total apolipoprotein concentrations, but do not differentiate among biochemically unique subtypes found in plasma [9]. Mass spectrometry assays were performed to determine whether subtypes of Apo A-II and Apo C-III differed in GDM cases and non-GDM controls over gestational time. The 2 most prominent forms of Apo $A$ in human plasma are monomeric and dimeric Apo A-II, with subtle changes in amino acid sequence leading to several forms of both monomer and dimeric Apo A-II [7,10]. Monomeric Apo A-II increased steadily over gestational time in control subjects, but GDM cases exhibited very little change in Apo A-II monomer from 4-12 to 16-22 weeks of gestation (Figure 1 and Table 4). Apo A-II dimer did not significantly change over gestational time in control subjects, but decreased significantly in GDM cases at $16-22$ weeks $(p=0.01, U=1)$ and approached a statistically significant decrease at $24-28$ weeks ( $p=0.08$, $\mathrm{U}=10$ ) (Figure 2 and Table 4). Relative abundance of dimeric Apo A-II was also quantitatively lower at 16-22 weeks in GDM cases relative to control subjects $(p=0.002, U=0$ ) (Figure 2B and Table 4). Plasma concentrations decreased slightly at 2428 weeks, but the difference was not statistically significant $(p=0.08, U=10)$ (Figure 2B and Table 4).

Glycosylated variants account for more than $97 \%$ of the proteins in maternal plasma, with sialylation being one of the most common glycovariants [11]. Unsialylated Apo C-III subtype (8800Da, Apo C-III ${ }_{0^{\prime}}$ Figure $3 \mathrm{~A}$ and Table 5) increased 
Flood Nichols et al. Journal of Diabetes Research \& Clinical Metabolism 2013,

http://www.hoajonline.com/journals/pdf/2050-0866-2-22.pdf

Table 2. Quantification of Apo A-II and Apo C-III in plasma from gestational diabetes patients and age-matched controls at 4-12 and 24-28 weeks by ELISA.

\begin{tabular}{|c|c|c|c|c|}
\hline & \multicolumn{4}{|c|}{ Apo A-II concentration (mg/dL) } \\
\hline & 4-12 weeks* & 24-28 weeks ${ }^{*}$ & P value ${ }^{\star *}$ & $\begin{array}{l}\text { U value } \\
(\text { critical } U)^{\star * *}\end{array}$ \\
\hline Control & $20(3)$ & $30(5)$ & 0.0516 & $22(21)$ \\
\hline \multirow{3}{*}{$\begin{array}{l}\text { Gestational } \\
\text { Diabetes }\end{array}$} & $24(4)$ & $26(3)$ & 0.653 & $21(8)$ \\
\hline & \multicolumn{4}{|c|}{ Apo C-III concentration (mg/dL) } \\
\hline & 4-12 weeks* & 24-28 weeks ${ }^{*}$ & P value ${ }^{\star *}$ & $\begin{array}{l}\text { U value } \\
(\text { critical } U)^{\star * *}\end{array}$ \\
\hline Control & $9(3)$ & $26(4)$ & 0.0003 & $\mathbf{0}(7)$ \\
\hline $\begin{array}{l}\text { Gestational } \\
\text { Diabetes }\end{array}$ & $10(2)$ & $24(4)$ & 0.006 & $0(4)$ \\
\hline
\end{tabular}

Data are expressed in concentrations of $\mathrm{mg} / \mathrm{dl}$ (median $(95 \%$ confidence interval)) for each patient ( $n=5$ GDM cases and 8 gestationally age-matched controls).

${ }^{\star}$ median ( $95 \%$ confidence intervals).

**, Mann-Whitney U test relative to 4-12 weeks.

$* * *$, critical value of $U$ for statistical significance at $\mathrm{p} \leq 0.05$.

Table 3. Quantification of HDL and VLDL/LDL in plasma from gestational diabetes patients and age-matched controls at 4-12 and 24-28 weeks gestation by quantitative enzymatic assay.

\begin{tabular}{|c|c|c|c|c|}
\hline & \multicolumn{4}{|c|}{ VLDL/LDL (mg/dL) } \\
\hline & 4-12 weeks ${ }^{*}$ & $\begin{array}{l}\text { 24-28 } \\
\text { weeks }^{\star}\end{array}$ & Pvalue ${ }^{\star *}$ & $\begin{array}{l}\text { U value } \\
(\text { critical } U)^{* * *}\end{array}$ \\
\hline Control & $144(25)$ & $232(48)$ & 0.004 & $1(7)$ \\
\hline \multirow{3}{*}{$\begin{array}{l}\text { Gestational } \\
\text { Diabetes }\end{array}$} & $161(10)$ & 191 (39) & 0.149 & $7(4)$ \\
\hline & \multicolumn{4}{|c|}{ HDL (mg/dL) } \\
\hline & 4-12 weeks* & $\begin{array}{l}\text { 24-28 } \\
\text { weeks }^{*}\end{array}$ & P value ${ }^{\star *}$ & $\begin{array}{l}\text { U value } \\
(\text { critical } U)^{* * *}\end{array}$ \\
\hline Control & $40(8)$ & $49(8)$ & 0.117 & $8(5)$ \\
\hline $\begin{array}{l}\text { Gestational } \\
\text { Diabetes }\end{array}$ & $46(11)$ & $46(8)$ & 0.500 & $12(4)$ \\
\hline
\end{tabular}

Data are expressed in concentrations of $\mathrm{mg} / \mathrm{dl}$ (median [95\% confidence interval]), $\mathrm{n}=5$ GDM cases and 8 gestationally age-matchedcontrols.

* median (95\% confidence interval).

**, Mann-Whitney U test relative to $4-12$ weeks.

${ }^{* * *}$, critical value of $U$ for statistical significance at $p \leq 0.05$.

significantly from $4-12$ weeks to $16-22$ weeks $(p=0.02, U=13)$ and $24-28$ weeks $(p=0.009, U=9)$ in the control subjects, but showed no appreciable change over gestational time in GDM cases (Figure 3B and Table 5). Relative abundance of Apo CIII was significantly higher in non-GDM controls than GDM cases at both $16-22$ weeks $(p=0.008, U=3)$ and $24-28$ weeks $(p=0.024$, $\mathrm{U}=6$ ) (Figure 3 and Table 5). In contrast, sialylated variants of the Apo C-III proteins at 9421 and 9712 Da (Apo C-III ${ }_{1}$ and Apo C-III ${ }_{2}$ ) significantly increased over gestational time in both cases and control subjects (Figures 3C and 3D and Table 5).
A

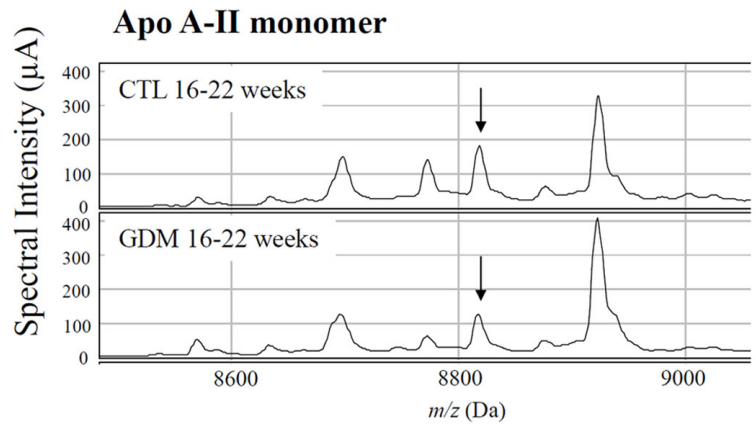

B

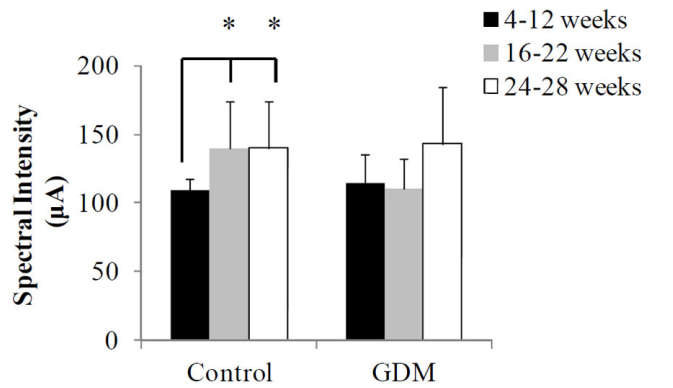

Figure 1. Lower rate of change in plasma Apo A-II monomer over gestational time in GDM than controls by mass spectrometry.

(A) Spectra are shown for a single representative GDM patient and age-matched control at gestational age range 16-22 weeks. Apo A-II monomer was identifiable at $8811 \mathrm{Da}$. Arrows denote peaks corresponding to Apo A-II monomers. CTL, age-matched controls; GDM, gestational diabetes mellitus.

(B) Quantification of median spectral intensities by SELDITOF mass spectrometry for $n=4-5$ GDM subjects and $n=8$ age-matched controls at each gestational age for Apo A-II monomer. Error bars denote $95 \%$ confidence intervals. ${ }^{*}, \mathrm{p}<0.05$ by Mann-Whitney U test relative to $4-12$ weeks.

\section{Discussion}

Our study reports 3 principal findings: (1) differences in apolipoprotein profiles are discernible in women destined to develop GDM compared touncomplicated controls as early as the second trimester by mass spectrometry spectral profile, but not ELISA assays; (2) dimeric Apo A-II decreases more significantly in GDM cases than non-GDM controls in the second trimester; and (3) plasma abundance of monomeric Apo A-II and unsialylated Apo C-III increases over gestational time in non-GDM controls, but not in GDM cases.

Transport of apolipoproteins and cholesterol are vital adaptive mechanisms in pregnancy that support fetal development. Pregnancy is a hyperlipidemic state in which the placenta and fetal adrenal cortex cooperatively produce cholesterol vital for fetal neuronal and membrane development [12]. The biochemical changes in GDM cases reflect fundamental alterations in the balance between carbohydrate and lipid regulation. In GDM, disruption in the balance of VLDL/LDL and HDL-associated apolipoproteins 
A Apo A-II dimer

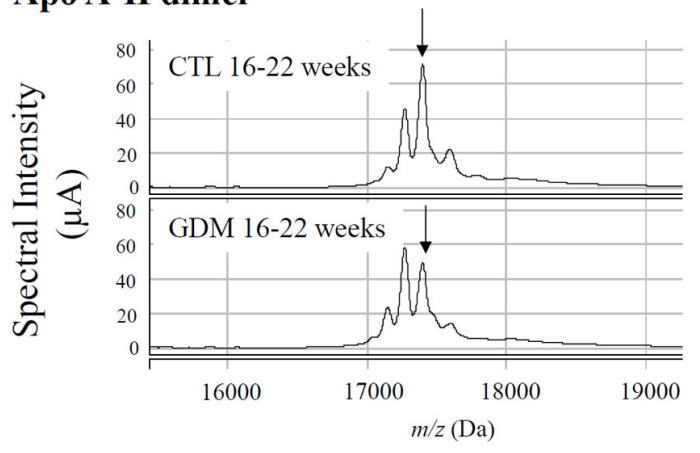

B Apo A-II dimer

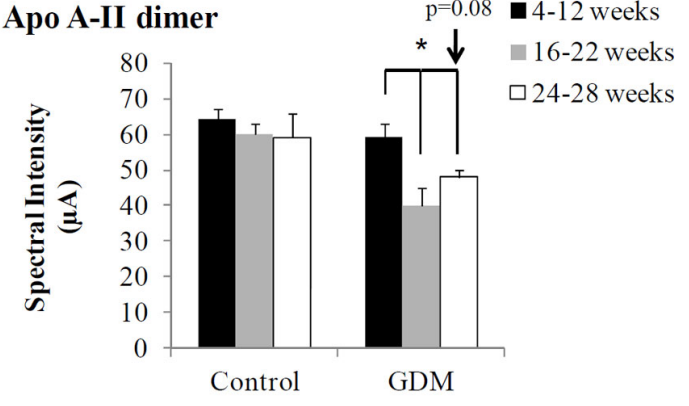

Figure 2. Decrease in Apo A-II dimer at 16-22 weeks in GDM cases relative to controls by mass spectrometry. (A) Spectra are shown for a single representative GDM patient and age-matched control at gestational age range 16-22 weeks for Apo A-II dimer, 17.4kDa.

(B) Quantification of median spectral intensities by SELDITOF mass spectrometry for $n=4-5$ GDM subjects and $n=8$ age-matched controls at each gestational age for Apo A-II dimer. Error bars denote $95 \%$ confidence intervals. *, $\mathrm{p}<0.05$ by Mann-Whitney $\mathrm{U}$ test relative to $4-12$ weeks.

and triglycerides could represent a result or an underlying causative pathology for the associated fetal and maternal morbidities. Placental apolipoprotein $D$ has recently been reported as an adaptation to GDM, possibly providing an important control protecting against oxidative stress [13]. Changes in Apo A-II association with HDL may represent a similar adaptation to GDM affecting cholesterol transport in the blood. Lower apolipoprotein A-II could signal failure in transit of HDL cholesterol, adversely affecting glucose metabolism and lipid-carbohydrate homeostasis [5]. Apo C-III is most closely associated with transporting atherogenic VLDL and LDL cholesterols. The physiological role of Apo C-III sialylation is speculative, but may include prolonging hepatic clearance or affinity to lipoprotein lipase [14]. Although plasma HDL cholesterol levels were not significantly different between GDM cases and controls in our study, there may be differences between HDL subtypes which are undetectable using our enzymatic assay. Other researchers have reported that $\mathrm{HDL}_{3}$ is substantially different from controls in GDM subjects while other subtypes (1 and 2) show relatively little difference [15]. Taken together, our results and the current literature support a fundamental difference in lipid/carbohydrate metabolism between non-GDM controls and GDM cases over gestational time.

Identifying at-risk women early in their pregnancies and enacting effective treatment may reduce or prevent the fetal and maternal morbidities associated with gestational diabetes. Early biomarker testing in pregnancy is also simpler and lends itself to improved patient compliance then the multistep testing currently available. Availability of a reliable clinical test using multiple markers for GDM early in pregnancy could also lead to the development of more effective pharmacological and/or life-style intervention treatment strategies by providing a physiological context for novel pharmaceutical development [16]. In the United States, screening for gestational diabetes typically occurs between 24 and 28 weeks gestation with a one hour glucose challenge test. If this screening test is abnormal, the diagnosis of gestational diabetes is confirmed with a three hour glucose tolerance test sometime in the late second or third trimester. Ideally, if the 1 hour screening test is abnormal, the followon confirmatory testing would be ordered and scheduled in a timely manner. In clinical practice, however, this can be somewhat challenging because the patients need to be fasting and the additional testing is time-consuming for both patients and the laboratory. Therefore, the diagnosis of gestational diabetes can be delayed or even missed. By this point, the pathology may be too sufficiently established for treatment to be effective in reducing significant maternal and fetal/neonatal risks. Two randomized controlled trials have demonstrated perinatal and maternal benefit from treating gestational diabetes in pregnancy with reductions in preeclampsia, maternal weight gain, neonatal overgrowth, neonatal fat mass and shoulder dystocia $[5,6]$. Additionally, a recent systematic review concluded that treatment of GDM is associated with a reduction in the incidence of shoulder dystocia and macrosomia when compared to routine care [16].

Even though earlier detection and treatment of at-risk women has been proposed to improve maternal and fetal outcomes, a consistently recommended early screening test is not currently available [2]. Establishing an apolipoprotein pattern unique to gestational diabetes could allow for early detection and intervention well before the onset of clinical symptoms [17]. Mass spectrometry affords a more sensitive method than standard biochemical approaches (eg, ELISA assays) to evaluate more subtle changes in protein composition [18]. Our results are concordant with a recent study by Kim and colleagues reporting early changes in apolipoproteins in GDM cases using a comparable mass spectrometry approach [19]. Studies in biomarker development have increasingly highlighted the need for multiple diagnostic targets to improve detection [3]. The apolipoproteins are particularly attractive biomarker candidates because of their relative intra-individual stability in the human proteome, decreasing technical variability [17]. Including the apolipoproteins in such 


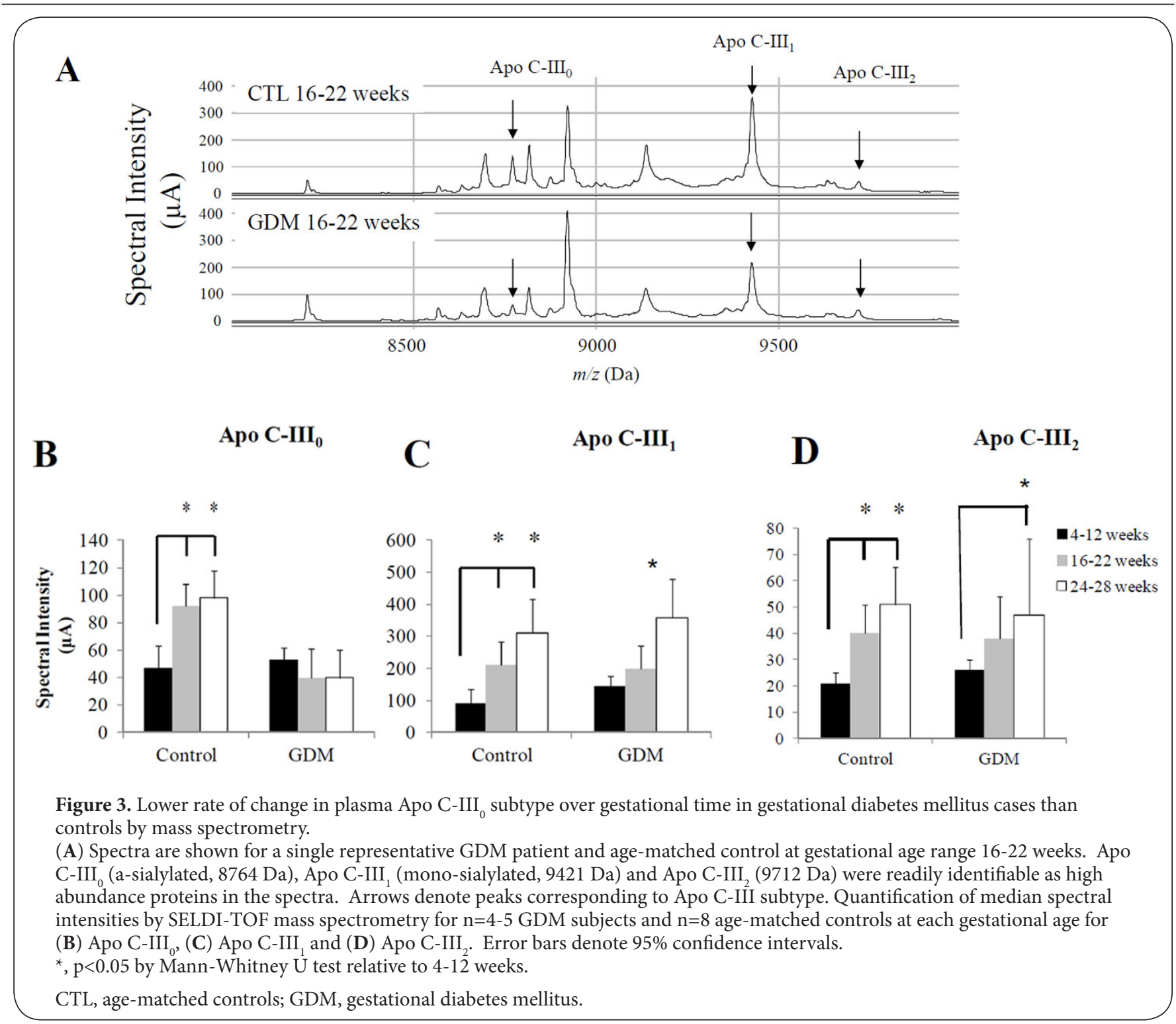

a multiplexed strategy may provide an internal biochemical standard for comparing relative concentrations of other biomarkers for GDM, thus improving diagnosis.

The strengths of our study include its longitudinal design and the use of mass spectrometry techniques capable of measuring changes in apolipoprotein subtypes which are undetectable by standard biochemical assays. We recognize that our study had a high attrition rate with a relatively small number of GDM cases in the final analyzable cohort. These data provide proof-of-principle for addressing the question of impaired lipid transport in a larger cohort of patients using the mass spectrometry approach we have developed in this study. Glucose concentrations are not routinely measured in nulliparous women before 24-28 weeks gestation; therefore, we could not confirm that the GDM cohort was euglycemic early in pregnancy. However, none of the women in our study had a history of diabetes outside of pregnancy, were morbidly obese (BMI >35), or had a strong family history of diabetes. We also relied on convenience sampling during routine clinical appointments. Patients were also not instructed to fast before any of the blood draws except for the 24-28 week sampling point. High fat or carbohydrate meals prior to phlebotomy may have influenced the apolipoprotein and/or cholesterol measurements reported in this study. However, both cases and controls were subject to the same sampling intervals and so diet-related changes would have equally affected both cohorts.

\section{Conclusions}

In conclusion, our study provides important insight into lipid dysregulation in GDM cases over gestational time. We report that the rate of change of apolipoproteins in patient plasma 
Flood Nichols et al. Journal of Diabetes Research \& Clinical Metabolism 2013, http://www.hoajonline.com/journals/pdf/2050-0866-2-22.pdf

Table 4. Statistical summary of differences in spectral intensity for SELDI-TOF MS spectra (A-II monomer and Apo A-II dimer) between GDM cases and gestationally age matched controls.

\begin{tabular}{|c|c|c|c|c|c|}
\hline \multicolumn{6}{|c|}{ Apo A-II monomer $(\mu \mathrm{A})$} \\
\hline & 4-12 weeks ${ }^{*}$ & $\begin{array}{l}\text { 16-22 } \\
\text { weeks }\end{array}$ & 24-28 weeks ${ }^{*}$ & $\begin{array}{l}\text { P value }{ }^{* *} \\
(16-22,24-28 \text { weeks })\end{array}$ & $\begin{array}{l}\text { U value (critical } U)^{* * *} \\
(16-22,24-28 \text { weeks) }\end{array}$ \\
\hline Control & $109(9)$ & $140(34)$ & $140(34)$ & $0.033,0.012$ & $14(15), 10(15)$ \\
\hline $\begin{array}{l}\text { Gestational } \\
\text { Diabetes }\end{array}$ & $115(20)$ & $110(22)$ & $143(41)$ & $0.417,0.201$ & $11(4), 8(7)$ \\
\hline \multicolumn{6}{|c|}{ Apo A-II Dimer $(\mu \mathrm{A})$} \\
\hline & 4-12 weeks ${ }^{*}$ & $\begin{array}{l}\text { 16-22 } \\
\text { weeks }\end{array}$ & 24-28 weeks ${ }^{\star}$ & $\begin{array}{l}\text { P value }{ }^{* *} \\
(16-22,24-28 \text { weeks })\end{array}$ & $\begin{array}{l}\text { U value (critical U) })^{\star * *} \\
(16-22,24-28 \text { weeks) }\end{array}$ \\
\hline Control & $65(6)$ & $57(6)$ & $61(13)$ & $0.735,0.397$ & $25(15), 29(15)$ \\
\hline $\begin{array}{l}\text { Gestational } \\
\text { Diabetes }\end{array}$ & $57(8)$ & $40(9)$ & $46(5)$ & $0.011,0.082$ & $1(4), 10(9)$ \\
\hline
\end{tabular}

Data are expressed as median spectral intensities $(\mu \mathrm{A})$ (median [ $95 \%$ confidence interval]) , $\mathrm{n}=4-5$

GDM cases and $n=8$ gestationally age-matchedcontrols.

${ }^{*}$ median $(95 \%$ confidence interval).

**, Mann-Whitney U test relative to $4-12$ weeks.

$* * *$, critical value of $\mathrm{u}$ for statistical significance at $\mathrm{p} \leq 0.05$.

Table 5. Statistical summary of differences in spectral intensity for SELDI-TOF MS spectra (Apo C-III, Apo C-III ${ }_{1}$ Apo C-III ${ }_{2}$ ) between GDM cases and gestationally age matched controls.

\begin{tabular}{|c|c|c|c|c|c|}
\hline \multicolumn{6}{|c|}{ Apo $\mathrm{C}-\mathrm{III}_{0}$ concentration $(\mu \mathrm{A})$} \\
\hline & 4-12 weeks ${ }^{\star}$ & $\begin{array}{l}\text { 16-22 } \\
\text { weeks }\end{array}$ & 24-28 weeks ${ }^{\star}$ & $\begin{array}{l}\text { P value } \\
(16-22,24-28 \text { weeks })\end{array}$ & $\begin{array}{l}\text { U value (critical } U)^{\star * *} \\
(16-22,24-28 \text { weeks) }\end{array}$ \\
\hline Control & $47(16)$ & $92(22)$ & $98(16)$ & $0.020,0.009$ & $13(15), 9(15)$ \\
\hline Gestational Diabetes & $53(9)$ & $40(16)$ & $40(21)$ & $0.149,0.417$ & $16(11), 11(4)$ \\
\hline \multicolumn{6}{|c|}{ Apo C-III ${ }_{1}$ concentration $(\mu \mathrm{A})$} \\
\hline & 4-12 weeks* & $\begin{array}{l}16-22 \\
\text { weeks }^{*}\end{array}$ & 24-28 weeks ${ }^{\star}$ & $\begin{array}{l}\text { P value } \\
(16-22,24-28 \text { weeks })\end{array}$ & $\begin{array}{l}\text { U value (critical U)*** } \\
(16-22,24-28 \text { weeks) }\end{array}$ \\
\hline Control & $91(45)$ & $212(71)$ & $312(104)$ & $0.007,0.001$ & $8(15), 3(15)$ \\
\hline Gestational Diabetes & $146(31)$ & $200(71)$ & $359(122)$ & $0.215, \mathbf{0 . 0 0 6}$ & $56(41), 0(4)$ \\
\hline \multicolumn{6}{|c|}{ Apo C-III ${ }_{2}$ concentration $(\mu \mathrm{A})$} \\
\hline & 4-12 weeks ${ }^{\star}$ & $\begin{array}{l}\text { 16-22 } \\
\text { weeks }\end{array}$ & 24-28 weeks ${ }^{\star}$ & $\begin{array}{l}\text { P value } \\
(16-22,24-28 \text { weeks })\end{array}$ & $\begin{array}{l}\text { U value (critical U) })^{\star * *} \\
(16-22,24-28 \text { weeks) }\end{array}$ \\
\hline Control & $21(4)$ & $40(11)$ & $51(14)$ & $0.003,0.001$ & $5(15), 3(15)$ \\
\hline Gestational Diabetes & $26(4)$ & $38(16)$ & $47(29)$ & $0.444, \mathbf{0 . 0 1 8}$ & $67(41), 2(4)$ \\
\hline
\end{tabular}

Data are expressed as median spectral intensities $(\mu \mathrm{A})$ (median [95\% confidence interval) , $\mathrm{n}=4-5 \mathrm{GDM}$

cases and $n=8$ gestationally age-matchedcontrols.

${ }^{*}$ median (95\% confidence interval).

**, Mann-Whitney U test relative to $4-12$ weeks.

$* * *$, critical value of $U$ for statistical significance at $p \leq 0.05$.

is significantly lower in GDM cases than non-GDM controls and that these differences are biochemically measurable by the second trimester. These results provide evidence for biomarker development and pharmacological intervention earlier than current practice.

\section{Competing interests}

The authors declare that they have no competing interests.

\section{Authors' contributions}

SKF-N extracted patient medical data from charts and confirmed diagnoses. SKF-N and MAL interpreted the clinical data, reviewed patient records, contributed to data interpretation and discussion of clinical relevance and assisted in drafting the manuscript. AJH, MSC and DLI conducted the mass spectrometry and ELISA assays. MTM and PGN supervised the study and edited the manuscript. DLI and MTM conceived of the study design, assisted in data analysis, collection and interpretation and wrote the manuscript.

\section{Acknowledgement}

We thank Cindy Kirker for library support, Dr. Raywin Huang for assistance with the statistical analyses and 
Ms. Deborah Tinnemore for reviewing the manuscript.

\section{Publication history}

Editor: Carol J. Homko, Temple University, USA.

Received: 22-May-2013 Revised: 23-May-2013

Accepted: 22-Jun-13 Published: 28-Jun-2013

\section{References}

1. Hartling L, Dryden DM, Guthrie A, Muise MA, Vandermeer B, Aktary WM, Pasichnyk D, Seida JC and Donovan L: Screening and diagnosing gestational diabetes mellitus. Evidence Report/Technology Assessment No. 210 12:ES2-ES7. | Book

2. ACOG Practice Bulletin. Clinical management guidelines for obstetrician-gynecologists. Number 30, September 2001 (replaces Technical Bulletin Number 200, December 1994). Gestational diabetes Obstet Gynecol 2001, 98:525-38. I PubMed

3. Georgiou HM, Lappas M, Georgiou GM, Marita A, Bryant VJ, Hiscock R, Permezel M, Khalil Z and Rice GE: Screening for biomarkers predictive of gestational diabetes mellitus. Acta Diabetol 2008, 45:157-65. | Article | PubMed

4. Coustan DR, Lowe LP, Metzger BE and Dyer AR: The Hyperglycemia and Adverse Pregnancy Outcome (HAPO) study: paving the way for new diagnostic criteria for gestational diabetes mellitus. Am J Obstet Gynecol 2010, 202:654 e1-6. | Article | PubMed Abstract | PubMed Full Text

5. Crowther CA, Hiller JE, Moss JR, McPhee AJ, Jeffries WS and Robinson JS: Effect of treatment of gestational diabetes mellitus on pregnancy outcomes. N Engl J Med 2005, 352:2477-86. | Article | PubMed

6. Landon MB, Spong CY, Thom E, Carpenter MW, Ramin SM, Casey B, Wapner RJ, Varner MW, Rouse DJ, Thorp JM, Jr., Sciscione A, Catalano P, Harper M, Saade G, Lain KY, Sorokin Y, Peaceman AM, Tolosa JE and Anderson GB: A multicenter, randomized trial of treatment for mild gestational diabetes. N Engl J Med 2009, 361:1339-48. | Article | PubMed Abstract | PubMed Full Text

7. Bondarenko PV, Cockrill SL, Watkins LK, Cruzado ID and Macfarlane RD: Mass spectral study of polymorphism of the apolipoproteins of very low density lipoprotein. J Lipid Res 1999, 40:543-55. | Article | PubMed

8. Harvey SB, Zhang Y, Wilson-Grady J, Monkkonen T, Nelsestuen GL, Kasthuri RS, Verneris MR, Lund TC, Ely EW, Bernard GR, Zeisler $\mathrm{H}$, Homoncik M, Jilma B, Swan T and Kellogg TA: O-glycoside biomarker of apolipoprotein $\mathrm{C} 3$ : responsiveness to obesity, bariatric surgery and therapy with metformin, to chronic or severe liver disease and to mortality in severe sepsis and graft vs host disease. J Proteome Res 2009, 8:603-12. | Article | PubMed

9. Flood-Nichols SK, Tinnemore D, Wingerd MA, Abu-Alya AI, Napolitano PG, Stallings JD and Ippolito DL: Longitudinal analysis of maternal plasma apolipoproteins in pregnancy: a targeted proteomics approach. Mol Cell Proteomics 2013, 12:55-64. | Article I PubMed

10. Jin $Y$ and Manabe $T$ : Direct targeting of human plasma for matrixassisted laser desorption/ionization and analysis of plasma proteins by time of flight-mass spectrometry. Electrophoresis 2005, 26:2823-34. Article I PubMed

11. Putnam FW (ed.): The Plasma Proteins: Structure, Function and Genetic Control. Orlando, FL: Academic press, Inc.; 1984. I Book

12. Ashwood ER: Clinical Chemistry of Pregnancy. In Burtis CA, Ashwood ER and Bruns DE (Eds.), Tietz Textbook of Clinical Chemistry and Molecular Diagnostis. 2006, 2153-2206.

13. Navarro A, Alonso A, Garrido P, Gonzalez C, Gonzalez Del Rey C, Ordonez $\mathrm{C}$ and Tolivia J: Increase in placental apolipoprotein $\mathrm{D}$ as an adaptation to human gestational diabetes. Placenta 2010, 31:25-31. | Article | PubMed

14. Wahrenbrock M, Borsig L, Le D, Varki N and Varki A: Selectin-mucin interactions as a probable molecular explanation for the association of Trousseau syndrome with mucinous adenocarcinomas. J Clin Invest 2003, 112:853-62. | Article | PubMed Abstract | PubMed Full Text

15. Merzouk H, Madani S, Korso N, Bouchenak M, Prost J and Belleville J:
Maternal and fetal serum lipid and lipoprotein concentrations and compositions in type 1 diabetic pregnancy: relationship with maternal glycemic control. J Lab Clin Med 2000, 136:441-8. | Article I PubMed

16. Horvath K, Koch K, Jeitler K, Matyas E, Bender R, Bastian H, Lange S and Siebenhofer A: Effects of treatment in women with gestational diabetes mellitus: systematic review and meta-analysis. BMJ 2010, 340:c1395. | Article I PubMed Abstract | PubMed Full Text

17. Nelsestuen GL, Zhang Y, Martinez MB, Key NS, Jilma B, Verneris M, Sinaiko $A$ and Kasthuri RS: Plasma protein profiling: unique and stable features of individuals. Proteomics 2005, 5:4012-24. | Article | PubMed

18. Buhimschi IA, Buhimschi CS, Weiner CP, Kimura T, Hamar BD, Sfakianaki AK, Norwitz ER, Funai EF and Ratner E: Proteomic but not enzyme-linked immunosorbent assay technology detects amniotic fluid monomeric calgranulins from their complexed calprotectin form. Clin Diagn Lab Immunol 2005, 12:837-44. | Article | PubMed

19. Kim SM, Park JS, Norwitz ER, Lee SM, Kim BJ, Park CW, Jun JK, Kim CW and Syn HC: Identification of proteomic biomarkers in maternal plasma in the early second trimester that predict the subsequent development of gestational diabetes. Reprod Sci 2012, 19:202-9. | Article | PubMed

\section{Citation:}

Flood Nichols SK, Lutgendorf MA, Mesngon MT, Harroun AJ, Cesarini MS, Napolitano PG and Ippolito DL: Impaired lipid transport in gestational diabetes mellitus. J Diab Res Clin Met 2013, 2:22.

http://dx.doi.org/10.7243/2050-0866-2-22 